analysis is correct. Very infrequently does one now hear of renal units being oversubscribed with patients in contrast to conditions of 10 years ago. I suspect that you are correct in suggesting that potential patients are not referred because it is believed that facilities are too limited. Over the past four years I have had the opportunity of selecting dialysis patients and have declined only five. One was over 70 , three had advanced vascular disease, and one was a heroin addict. The point is clear; the profession, like the media, think there are insufficient kidney machines. You have profitably indicated that insufficient patients are referred.

Although the number of units and equipment therein is adequate for the number of patients currently treated, maximal use of dialysis facilities is limited by the availability of trained nurses. Some units can dialyse only by day for lack of nurses. Rather than the provision of more machines, consideration should be given to ways of attracting nurses to work in renal units and funds allocated for an increase in their salaries.

Roger GABRIEL

Department of Renal Medicine,

St Mary's Hospital,
London W2

SIR,-Your leading article (25 November, p 1449), while giving an admirable objective review of the selection of patients for dialysis and transplantation as practised in the United States of America, Japan, Continental countries, and Britain, does not take into consideration the wide variation in the organisation of the health systems in these countries. It is justifiable to measure strength with our partners, but any direct comparison made would not be valid, for the nephrological services provided by any of these countries is roughly correlated to the nation's wealth. ${ }^{1}$ Whereas in some countries it may be possible to treat schizophrenia and psoriasis through haemodialysis, the same becomes ethically unjustifiable in a country which lacks finances for its basic services.

Realising the shortcomings of the home dialysis programme, I feel we should not jump on the bandwagon and go flat out to open centres for, as you wisely call it, "hospital dialysis in, for example, so-called satellite or self-care units." Confusing terminology has evolved to describe such units in order to satisfy the physicians' whims. As I see it, home dialysis is true self-care, whereas other modes of therapy-namely, limited care, minimal care, assisted care, and satellite dialysis, are all various other names for hospital dialysis. I have suggested yet another form of centre dialysis-that is, "community dialysis." by a trained paramedical person (helper) outside the hospitals. Such trained personnel are already available in Britain in the form of artificial kidney assistants. Learning from the American experience, we do run a risk of

Comparison of dialysis population with transplanted patients ${ }^{4}$

\begin{tabular}{|c|c|c|c|c|c|c|c|}
\hline \multirow[t]{2}{*}{ Country } & \multirow{2}{*}{$\begin{array}{l}\text { Population } \\
\text { (millions) }\end{array}$} & \multicolumn{3}{|c|}{ No of patients on dialysis } & \multicolumn{3}{|c|}{$\begin{array}{l}\text { No of patients with functioning } \\
\text { transplant }\end{array}$} \\
\hline & & 1975 & 1976 & 1977 & 1975 & 1976 & 1977 \\
\hline $\begin{array}{l}\text { West } \\
\text { Germany } \\
\text { France } \\
\text { Italy } \\
\text { U.K. }\end{array}$ & $\begin{array}{l}62 \\
52 \\
56 \\
56\end{array}$ & $\begin{array}{l}5056 \\
4650 \\
4189 \\
2168\end{array}$ & $\begin{array}{l}5946 \\
5650 \\
5265 \\
2423\end{array}$ & $\begin{array}{l}7357 \\
6600 \\
5713 \\
2576\end{array}$ & $\begin{array}{r}299 \\
686 \\
288 \\
1250\end{array}$ & $\begin{array}{r}425 \\
841 \\
401 \\
1501\end{array}$ & $\begin{array}{r}478 \\
940 \\
503 \\
1785\end{array}$ \\
\hline
\end{tabular}

having on our hands expensive doctor-cumnurse-supervised satellite units. It is cheaper to dialyse with the aid of a paid helper at home than to use hospital facilities. ${ }^{3}$

Whether the increase in hospital dialysis population would necessarily result in an increased pool of renal transplanted patients is debatable. In Continental countries, in with an ever-increasing population of patients on hospital dialysis, their transplant patient pool is no higher than ours (see table below).

The UK home dialysis service has developed into an enviable institution which should not only be maintained but allowed to progress at the current rate.

Renal Dialysis Unit,

RASHEED AHMAD

Sefton General Hospital, Liverpool

Parkin, D M, in Living with Renal Failure, ed J L Anderton, F M Parsons, and D E Jones. Lancaster, MTP, 1978 .

Symposium, in United Kingdom and Ireland Dialysis 1975 .

${ }^{3}$ Kolff, W J, Artificial Organs, 1978, 1, 8.

roceedings of the European Dialysis and Transplantation Association, 1976, 13, 8, 1977, 14, 16, and 1978,

\section{Behcet's disease}

SIR,-We noted with interest your leading article on Behçet's disease (22 July, p 234). We agree that the majority of these patients eventually present in rheumatology clinics. The high incidence of the disease in the Middle East is supported by our experience. One of us (MM) saw one new patient with Behçet's disease in one year while working in a large rheumatology research centre in Glasgow Royal Infirmary. In the past 12 months in Riyadh we have seen 14 patients with Behçet's disease. They all came from two unrelated families. The pattern of the disease was unusual in that there was strong presumptive evidence of an infective aetiology and of the disease being susceptible to hormonal influence.

All those affected had the classical features of the disease-that is, painful oral ulcers with genital ulceration, iritis, and asymmetrical arthritis.

In the first family the father was initially affected and after one year of marriage his wife, who was unrelated and previously healthy, developed the disease. She noticed that pregnancy caused severe and prolonged exacerbations of her arthritis and ulcers. Only at the menopause did she become free from children, eight of whom developed Behçet's disease. Six daughters and two sons are affected and all developed the disease after puberty. Two of her daughters have married and after approximately one year of marriage their previously healthy husbands have developed the disease. Neither were consanguineous marriages. Both women have spite of the liberal organ donation laws and all symptoms of the disease. She had 10 noticed that their symptoms are aggravated by the contraceptive pill and pregnancy.

In the second family, which is completely unrelated to the first, a woman developed the disease five years after marriage to a man with active Behçet's disease. She also has observed that pregnancy makes her symptoms very much worse. The pattern of the disease in the two families would support the hypothesis of the disease being infective in origin and, in view of the long incubation period, infection with a slow virus is a possibility. So far as we are aware the influence of pregnancy and the contraceptive pill on the course of the disease has not been observed before.

Department of Medicine,

MONIR MADKOUR

Department of Medicin
Al-Kharj Hospital,

AIDA KUDWAH

Riyadh, Saudi Arabia

\section{Retroperitoneal fibrosis after treatment} with atenolol

SIR,-We wish to report the following illness which occurred in a patient receiving treatment with the beta-blocker atenolol (Tenormin).

A 68-year-old woman consulted her general practitioner because of vague ill health, was found to be hypertensive, and was started on atenolol $100 \mathrm{mg}$ daily. Six months later she was admitted to hospital because of vomiting and abdominal pain, but the only abnormality found on investigation was a high erythrocyte sedimentation rate $(114 \mathrm{~mm}$ in $1 \mathrm{~h})$. The blood urea concentration was $7.3 \mathrm{mmol} / 1$ $(44 \mathrm{mg} / 100 \mathrm{ml})$ at this time. Her symptoms settled spontaneously but three months later she was readmitted in an acute confusional state. Investigations showed a blood urea concentration of $37.2 \mathrm{mmol} / 1(224 \mathrm{mg} / 100 \mathrm{ml})$ and dilated upper renal tracts on intravenous pyelography. Laparotomy showed extensive retroperitoneal fibrosis, and after bilateral ureterolysis her mental state and renal function returned to normal.

The only other drugs taken by the patient before this illness were oral iron preparations, metoclopramide, and ibuprofen. We report this case because of the established relationship between the earlier beta-blocker practolol and similar types of sclerosing fibroblastic reaction.

C C DOHERTY MaRY G MCGEOWN R A DONALDSON

\section{Renal Unit,}

Belfast City Hospital, Belfast

\section{Hazards of sulphinpyrazone}

SIR,-Recent claims that the administration of sulphinpyrazone (Anturan) can markedly improve the survival rate after recovery from acute myocardial infarction are based on a single large multicentre trial in North America. ${ }^{12}$ Since this drug is now being extensively advertised, it is important to be aware of its hazards.

We wish to report the occurrence of a severe gastrointestinal haemorrhage in a man of 63 with a history of hypertension, stroke, and myocardial infarction who was on concurrent anticoagulant therapy. Prior to the introduction by his general practitioner of sulphinpyrazone $200 \mathrm{mg}$ four times daily his prothrombin time had been maintained within the therapeutic range on warfarin $8 \mathrm{mg}$ daily. One week after starting sulphinpyrazone he 
developed abdominal pain. Two days later he passed a melaena stool and was admitted to hospital.

On admission his haemoglobin level had fallen to $8.5 \mathrm{~g} / \mathrm{dl}$ and his prothrombin time was greater than $3 \mathrm{~min}$. Extensive generalised haemorrhage into the tissues was revealed by the later appearance of Cullen's sign and bruising on the legs. Despite blood transfusion and correction of the prothrombin time with vitamin $\mathrm{K}$ he survived the haemorrhage only to succumb to intractable cardiac failure three weeks later. Permission for postmortem examination was not obtained

In-vitro studies have shown that sulphinpyrazone will displace oral anticoagulants from their plasma binding sites, ${ }^{3}$ and it has been suggested that this drug was responsible for potentiation of warfarin activity in a patient. The manufacturers are aware of this potential danger and suggest that frequent estimations of the prothrombin time should be undertaken when these drugs are given concurrently and that the anticoagulant dosage be adjusted accordingly. There are considerable difficulties in implementing this in practice and we fee that the use of sulphinpyrazone outside of hospital is contraindicated in patients on oral anticoagulants.

\section{Mattingly}

MARY BRADLEY P J SELLEY

\footnotetext{
Royal Devon and Exeter Hospital

(Wonford),

Anturane Reinfarction Trial Research Group, New England Fournal of Medicine, 1978, 298, 289.

British Medical fournal, 1978, 1, 941.

erler, K, and Duckert, F, Thrombosis et Diathesis

Haemorrhagica, 1968, 19, 389.

Medicine, 1978, 299, 955 , New England fournal of
}

Costs and benefits of serum $x$-fetoprotein screening

SIR,-A recent radio broadcast by Kennedy will have stimulated heart-searching among the public and the profession about the usefulness of serum $x$-fetoprotein (AFP) screening. Kennedy calculated that a national screening programme might sacrifice 205 normal or nearnormal fetuses per year to prevent the birth of 329 babies with severe spina bifida. This gives a cost-benefit ratio of 205:329 or 0.62. To test the objectivity of this calculation, I have used an interactive computer program (ARAFP-2) to calculate the ratio and to see how it varies as the assumptions used are changed.

I find that the cost-benefit ratio can range from 0.11 to 0.30 using different reasonable assumptions, but it never reaches Kennedy's figure of 0.62 . This is partly because Kennedy omits the abortion of all anencephalics from the benefit side, which does not seem very justifiable (since he does count those fetuses with spina bifida which are stillborn). The most important factor in achieving a favourable ratio is to keep the amniocentesis rate (the proportion of the screened population who receive amniocentesis) as low as possible. Table I shows data for a population with 1.81 cases of anencephaly, 1.74 of spina bifida, ${ }^{2}$ and 0.2 of exomphalos ${ }^{3}$ per 1000 pregnancies screened. Provided that the amniocentesis rate is kept low, the cost-benefit ratio is surprisingly insensitive to changes in the risk of fetal loss due to amniocentesis. Kennedy assumed $1.5^{\circ}$, fetal loss; table I assumes $1^{\prime \prime} "$, and table II shows the effect of changes in this figure. Table III shows that the ratio varies relatively little with the incidence of neural tube defect, a point which is relevant when proposals to
TABLE I-Effect of amniocentesis rate on the costbenefit ratio

\begin{tabular}{|c|c|c|c|c|}
\hline \multicolumn{2}{|c|}{ Amniocenteses } & \multicolumn{2}{|c|}{$\begin{array}{l}\text { No of fetuses lost } \\
\text { or terminated* }\end{array}$} & \multirow{2}{*}{$\begin{array}{l}\text { Cost- } \\
\text { benefit } \\
\text { ratio }\end{array}$} \\
\hline Rate & No* & $\begin{array}{l}\text { Severely } \\
\text { affected }\end{array}$ & $\begin{array}{l}\text { Normal or } \\
\text { mildly } \\
\text { affected }\end{array}$ & \\
\hline $\begin{array}{l}0.5 \\
1.0 \\
2 \cdot 0 \\
3.0\end{array}$ & $\begin{array}{r}2205 \\
4410 \\
8820 \\
13230\end{array}$ & $\begin{array}{l}1137 \\
1156 \\
1195 \\
1233\end{array}$ & $\begin{array}{l}173 \\
208 \\
277 \\
347\end{array}$ & $\begin{array}{l}0.152 \\
0 \cdot 180 \\
0 \cdot 232 \\
0.281\end{array}$ \\
\hline
\end{tabular}

*Numbers based on screening 441000 pregnancies. ${ }^{1}$

TABLE II-Effect on cost-benefit ratio of changes in fetal loss due to amniocentesis

\begin{tabular}{|c|c|c|c|}
\hline \multirow{2}{*}{$\begin{array}{c}\text { Amniocentesis } \\
\text { rate }\end{array}$} & \multicolumn{3}{|c|}{ Cost-benefit ratio } \\
\hline & $\begin{array}{c}0.5 " \prime \\
\text { fetal loss }\end{array}$ & $\begin{array}{c}1^{\prime} \\
\text { fetal loss }\end{array}$ & $\begin{array}{c}1.5^{\circ} \\
\text { fetal loss }\end{array}$ \\
\hline $\begin{array}{l}0.5 \\
1 \cdot 0 \\
2 \cdot 0\end{array}$ & $\begin{array}{l}0 \cdot 144 \\
0 \cdot 163 \\
0.197\end{array}$ & $\begin{array}{l}0 \cdot 152 \\
0 \cdot 180 \\
0 \cdot 232\end{array}$ & $\begin{array}{l}0 \cdot 160 \\
0 \cdot 197 \\
0 \cdot 267\end{array}$ \\
\hline
\end{tabular}

TABLE III-Cost-benefit ratio and incidence of neural tube defect

\begin{tabular}{|c|c|c|c|}
\hline \multicolumn{2}{|c|}{$\begin{array}{l}\text { Rate per thousand } \\
\text { pregnancies }\end{array}$} & \multicolumn{2}{|c|}{$\begin{array}{l}\text { Cost-benefit ratio with } \\
1 \text { ". fetal loss }\end{array}$} \\
\hline Anencephaly & $\begin{array}{l}\text { Spina } \\
\text { bifida }\end{array}$ & $\begin{array}{c}1 " \prime \\
\text { amniocentesis }\end{array}$ & $\begin{array}{c}2 \% \\
\text { amniocentesis }\end{array}$ \\
\hline $\begin{array}{l}1.81 \\
2.5 \\
5.0\end{array}$ & $\begin{array}{l}1.74 \\
2.5 \\
5.0\end{array}$ & $\begin{array}{l}0 \cdot 180 \\
0 \cdot 158 \\
0 \cdot 128\end{array}$ & $\begin{array}{l}0.232 \\
0.198 \\
0.152\end{array}$ \\
\hline
\end{tabular}

screen only in areas of high incidence are considered.

It is interesting to compare these ratios with those for the established practice of offering amniocentesis to women who have had a previous baby with neural tube defect. We expect $3-5^{\circ}$, abnormal fetuses in this group." On the assumption of $1^{\circ}$ ofetal loss due to amniocentesis and $0 \cdot 2^{\circ}$, false positives (as in table I), the cost-benefit ratio is $0 \cdot 41-0.60$, which is worse than can be obtained in any conceivable serum AFP screening programme. The reason for this is that serum AFP screening defines a group with a particularly high proportion of abnormal fetuses." It appears that a serum AFP screening programme, in which not more than $1^{\circ} \circ$ of those screened receive amniocentesis, would achieve a better cost-benefit ratio than the currently accepted practice of offering routine amniocentesis to women who have had a baby with neural tube defect.

Department of Medical Genetics,

ANDREW P READ

University of Manchester

Kennedy, J, The Defect, BBC Radio 4, 31 October

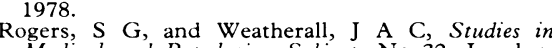
Tedical and Population Subjects No 32. London, HMSO, 1976

Birth Defects: Atlas and Compendium, ed D Bergsma National Foundation-March of Dimes). Baltimore, Williams and Wilkins, 1973

Clinical Genetics Society Working Party on Amniocentesis in Relation to Genetic Counselling.

Eugenics Review, in press.
Ferguson-Smith, M A, et al, Lancet, 1978, 1, 1330.

\section{Seizure following lumbar myelography} with metrizamide

SIR,-In recent years water-soluble media have been used for lumbar myelography. Meglumine iocarmate has been found in some cases to be associated with severe muscle spasm leading to central fracture dislocation of the hip. ${ }^{1}$ This has led to the more general use of metrizamide. Complications, however, may occur with this latter medium ${ }^{2}$ and we report a case in which a grand-mal seizure occurred shortly after its use.

A 24-year-old factory worker presented with clinical evidence of a prolapsed intervertebral disc. Lumbar myelography was carried out using $10 \mathrm{ml}$ of metrizamide solution with a concentration of $170 \mathrm{mg} / \mathrm{ml}$. The patient was instructed to sit upright out of bed for six hours. The following morning he had a grand-mal seizure. There was no past or family history of epilepsy, neither did the patient take neuroleptics, antidepressants, or chlorpromazine.

Grand-mal seizures are not unknown following the use of metrizamide. ${ }^{2}$ We would therefore make three suggestions. Firstly, that our indications for myelography should remain strict. Secondly, that although the manufacturers suggest that patients may lie nearly flat following the procedure, they should preferably remain sitting up for a couple of hours to lessen the danger of contact of the medium intracranially. Lastly, that patients should not be managed as outpatients and should remain in hospital for $24 \mathrm{~h}$ after myelography.

\section{A RICHARD WRAY} J TEMPLETON JAMES D LAIRD

Altnagelvin Hospital,
Londonderry, NI

' Eastwood, J B, Parkes, B, and Reid, B R, British Medical fournal, 1978, 1, 692 suppl 355, p 409.

\section{Quality control}

SIR,-I share the misgivings expressed by Dr C A K Bird and Mr C B Brownhill (2 December, p 1573) about the quality of biochemical assays performed in ward side rooms.

Our hospital pharmacy regularly issues Dextrostix to 38 wards and clinics. Twice this year, in August and November, I offered the sisters in charge of these units the opportunity to participate in a quality control scheme. Those who took part were each sent a sample to be analysed for glucose level with Dextrostix. I collated their results and sent each participant a report showing all the results but identifying only their own result, the laboratory's finding, and the ascribed glucose content of the sample. I undertook not to reveal the results obtained by individual units to any third party.

In August four wards and in November 11 wards out of the 38 participated. On both occasions two wards produced results so inaccurate that if the samples had come from a patient clinical action based on them would have been inappropriate. Also, although our laboratory has been reporting in SI units for nearly two years, more than two-thirds of the results sent in by the wards and clinics were in $\mathrm{mg} / 100 \mathrm{ml}$.

Dextrostix and other techniques for extralaboratory biochemical analyses, used properly, are an invaluable aid for the clinician. Used in an incompetent manner they can be a grave hazard to the patient.

I am grateful to Miss $\mathrm{H}$ M Chadwick of Ames Co for a gift of Tek-chek quality control material.

\section{A $\mathrm{R}$ W FORREST}

Department of Clinical Chemistry,

Royal Berkshire Hospital

Reading 